\title{
Gas and particle size distributions of polychlorinated naphthalenes in the atmosphere of Beijing, China ${ }^{\text {is }}$
}

\author{
Qingqing Zhu, Xian Zhang, Shujun Dong, Lirong Gao, Guorui Liu, Minghui Zheng* \\ State Key Laboratory of Environmental Chemistry and Ecotoxicology, Research Center for Eco-Environmental Sciences, Chinese Academy of Sciences, Beijing
} 100085, China

\section{A R T I C L E I N F O}

\section{Article history:}

Received 15 September 2015

Received in revised form

22 January 2016

Accepted 23 January 2016

Available online 1 February 2016

\section{Keywords:}

Atmosphere

Polychlorinated naphthalenes

Particle size distribution

Health risk assessment

\begin{abstract}
A B S T R A C T
Polychlorinated naphthalenes (PCNs) were listed as persistent organic pollutants in the Stockholm Convention in 2015. Despite numerous studies on PCNs, little is known about their occurrence in atmospheric particulate matter of different sizes. In this study, 49 PCN congeners were investigated for their concentrations and size-specific distributions in an urban atmosphere, and preliminary exposure assessments were conducted. Ambient air samples were collected using a high-volume cascade impactor for division into a gas fraction and four particle size fractions. Samples were collected from October 2013 to June 2014 at an urban site in Beijing, China. The concentration range for PCNs in the atmosphere (gas + particle fractions) was $6.77-25.90 \mathrm{pg} / \mathrm{m}^{3}$ (average $16.28 \mathrm{pg} / \mathrm{m}^{3}$ ). The particle-bound concentration range was $0.17-2.78 \mathrm{pg} / \mathrm{m}^{3}$ (average $1.73 \mathrm{pg} / \mathrm{m}^{3}$ ). Therefore, PCNs were mainly found in the gas phase. The concentrations of PCNs in a fraction increased as the particle size decreased $\left(d_{a e}>10 \mu \mathrm{m}\right.$, $10 \mu \mathrm{m} \geq \mathrm{d}_{\mathrm{ae}}>2.5 \mu \mathrm{m}, 2.5 \mu \mathrm{m} \geq \mathrm{d}_{\mathrm{ae}}>1.0 \mu \mathrm{m}$ and $\left.\mathrm{d}_{\mathrm{ae}} \leq 1.0 \mu \mathrm{m}\right)$. Consequently, PCNs were ubiquitous in inhalable fine particles, and the $\Sigma$ PCNs associated with $\mathrm{PM}_{1.0}$ and $\mathrm{PM}_{2.5}$ reached $68.4 \%$ and $84.3 \%$, respectively. Tetra-CNs and penta-CNs (the lower chlorinated homologues) predominated in the atmosphere. The homologue profiles in different size particles were almost similar, but the particulate profiles were different from those in the gas phase. Among the individual PCNs identified, CN38/40, CN52/60 and CN75 were the dominant compounds in the atmosphere. CN66/67 and CN73 collectively accounted for most of the total dioxin-like TEQ concentrations of the PCNs. Exposure to toxic compounds, such as PCNs present in $\mathrm{PM}_{1.0}$ or $\mathrm{PM}_{2.5}$, may affect human health. This work presents the first data on size-specific distributions of PCNs in the atmosphere.
\end{abstract}

() 2016 Elsevier Ltd. All rights reserved.

\section{Introduction}

Polychlorinated naphthalenes (PCNs) are a group of compounds that are toxic, persistent and bioaccumulative. Their properties are similar to polychlorinated dibenzo-p-dioxins and dibenzofurans (PCDD/Fs) and polychlorinated biphenyls (PCBs) because of their similar structures (Bidleman et al., 2010). Although the production and use of PCNs have been banned in most countries, PCNs are still unintentionally produced and released into the environment via thermal-related processes (Liu et al., 2014). They have been detected in various matrices in the environment, including air, soil and sediment (Harner et al., 2006; Helm et al., 2008; Lee et al., 2007; Wang et al., 2012). Studies have suggested that PCNs are

\footnotetext{
th This paper has been recommended for acceptance by Charles Wong.

* Corresponding author.

E-mail address: zhengmh@rcees.ac.cn (M. Zheng).
}

absorbed into organisms, and they have been found in human serum (Fromme et al., 2015; Helm et al., 2008). Investigations have also shown that the contribution of PCNs to dioxin-like toxicity in some areas may overwhelm the contributions of PCDD/Fs and PCBs (Park et al., 2010). Because of their potential adverse effects on the environment and human health, PCNs have attracted increasing attention. Consequently, they have recently been listed as unintentional persistent organic pollutants at the 2015 Triple Conference of the Parties to the Stockholm Convention on Persistent Organic Pollutants.

Humans are directly exposed to PCNs in the atmosphere, and the atmosphere is a major medium for the transport and deposition of PCNs. In the atmosphere, PCNs are distributed between the gas phase and particle phase; the phase they are in greatly affects their environmental fate, including transport, transformation and removal processes (Bidleman, 1988; Harner and Bidleman, 1998). Because of their relatively high octanol-air partition coefficients, 
PCNs are usually present exclusively in the gas phase. Numerous epidemiological studies have illustrated that there is a strong exposure-response relationship between short-term effects of particulate air pollution (e.g., premature mortality and hospital admissions) and long-term or cumulative health effects (e.g., lung cancer, cardiovascular and respiratory diseases) (Brunekreef and Forsberg, 2005; Chen et al., 2012; Dominici et al., 2006).

Ultrafine and fine particles are present in the atmosphere for longer than larger particles, and are not removed efficiently by wet or dry deposition, which increases their atmospheric lifetimes (Aulinger et al., 2007; Kurokawa et al., 1998). Compared with larger particles, ultrafine and fine particles are present in higher numbers in the atmosphere, and have larger specific surface areas and more porous surfaces, which all results in higher adsorption and retention of semi-volatile pollutants such as PCNs (Valavanidis et al. 2008). It is well known that inhalable particles (such as $\mathrm{PM}_{10}$ ) are small enough to reach deeply into the lungs, and $\mathrm{PM}_{1.0}$ can enter the bloodstream, which may induce even higher risks than larger particles. Studies have reported that fine particles $(<0.5 \mu \mathrm{m})$ may be the main contributor among particulate matter (PM) fractions that cause adverse health effects from air pollution, and that adverse health effects may increase as the particle size decreases (Meng et al., 2013). Therefore, information on size-specific distributions of PCNs is needed to better understand and predict their transport in the atmosphere. This information could also be used for PCN exposure assessments. To date, the particle size distributions of many contaminants have been studied extensively, including for PCDD/Fs (Chao et al., 2003; Chuang et al., 2015; Kaupp and McLachlan, 2000; Oh et al., 2002), PCBs (Chrysikou et al., 2009; Chrysikou and Samara, 2009), n-alkanes (Bi et al., 2005), polycyclic aromatic hydrocarbons (PAHs) (Bi et al., 2005; Duan et al., 2007; Hien et al., 2007), pesticides (Coscollà et al., 2013), heavy metals (Zereini et al., 2005), halogenated flame retardants (Cao et al., 2014; Mandalakis et al., 2009; Okonski et al., 2014), hexabromocyclododecane (HBCD) (Ni and Zeng, 2013), tetrabromobisphenol A (TBBPA) (Ni and Zeng, 2013) and some other components (ions, organic matter and mineral matter) (Sánchez-Soberón et al., 2015). Previous studies of PCNs in the atmosphere have mainly focused on the gas phase (Hogarh et al., 2012b; Li et al., 2012) and there have been few studies of particle-bound PCNs or their size distributions.

Beijing, the capital city of China, has a high population density and heavy traffic. Recently, rapid economic growth has aggravated air pollution in the city and resulted in many pollution problems, including haze events that are correlated with high concentrations of ultrafine and fine particles. Hence, knowledge of the distribution of PCNs in different particle size fractions is crucial for understanding the environmental fate of these pollutants and to perform human health risk assessments.

In this study, the gas and particle phase concentrations of PCNs were determined along with their particle size distributions in the atmosphere in Beijing. Air samples collected during different periods were fractionated into a gas phase fraction and four PM fractions to investigate the distribution of PCNs. The results were used to assess the risk that PCNs in inhalable PM pose to human health. To the best of our knowledge, this is the first report on the size-specific distributions of PCNs in the atmosphere. This study will expand on current knowledge of PCN concentrations in the air in China.

\section{Materials and methods}

\subsection{Air sampling}

Ambient air samples were collected from October 2013 to June
2014 in Beijing $\left(116^{\circ} 12^{\prime} 28^{\prime \prime}\right.$ E, $\left.40^{\circ} 00^{\prime} 44^{\prime \prime} \mathrm{N}\right)$ using a high-volume cascade impactor (KS-303 PM10/2.5/1.0 sampler, Kálmán System, Hungary) with size-selective inlets. The sampling site was on the rooftop of a building and approximately $12 \mathrm{~m}$ above ground level. There were two roads near the sampling site, with about 30,000 vehicles/day. In the surrounding area there was a university campus, research institutes and residential areas, but no industrial buildings nearby.

The gas phase and four PM fractions $\left(\mathrm{d}_{\mathrm{ae}}>10 \mu \mathrm{m}\right.$, $10 \mu \mathrm{m} \geq \mathrm{d}_{\mathrm{ae}}>2.5 \mu \mathrm{m}, 2.5 \mu \mathrm{m} \geq \mathrm{d}_{\mathrm{ae}}>1.0 \mu \mathrm{m}$ and $\mathrm{d}_{\mathrm{ae}} \leq 1.0 \mu \mathrm{m}$ ) were collected simultaneously. The particles were collected onto quartz fiber filters (QFFs; Ahlstrom Munktell, Sweden), which were sized as shown in Supplementary Information (SI) Table S1. The gas phase was adsorbed onto polyurethane foam (PUF; Tisch Environmental, USA, $63 \mathrm{~mm}$ diameter and $76 \mathrm{~mm}$ length). Before sampling, the QFFs were baked at $450{ }^{\circ} \mathrm{C}$ to remove organic contaminants, and the PUFs were extracted by accelerated solvent extraction (Thermo Fisher Scientific, USA) with acetone. The impactor was operated at a constant flow rate of $24 \mathrm{~m}^{3} / \mathrm{h}$, and each sample was collected continuously for approximately $6 \mathrm{~d}$. This resulted in sampling an air volume of $\sim 3400 \mathrm{~m}^{3}$ per sample. Sampling details are given in SI Table S2. Before and after sampling, the QFFs were weighed using an analytical balance with a reading precision of $0.0001 \mathrm{~g}$ after stabilization in a constant temperature $\left(20 \pm 5{ }^{\circ} \mathrm{C}\right)$ and humidity ( $30 \pm 2 \%$ ) chamber (Sun et al., 2006). Then they were wrapped tightly in aluminum foil, sealed in plastic bags, and kept at $-18{ }^{\circ} \mathrm{C}$ until required for analysis. In total, six samples were collected, each consisting of a fraction of gas phase and four QFFs with size-specific fractions of PM.

\subsection{Sample extraction and analysis}

The tetra- to octachloro-CNs were analyzed by an established isotope dilution high-resolution gas chromatography/highresolution mass spectrometry method (Jiang et al., 2015; Liu et al., 2010). The samples were spiked with $1 \mathrm{ng}{ }^{13} \mathrm{C}_{10}$-labeled PCN internal standards (CN27, 42, 52, 67, 73 and 75), and then extracted by accelerated solvent extraction with dichloromethane and hexane $(1: 1, v: v)$. The sample extracts were concentrated and cleaned up using a series of chromatography columns, including a multilayer silica gel column, a basic alumina column and an activated carbon column. The activated carbon column was used to separate PCNs from interfering components. Finally, the extracts were concentrated to approximately $20 \mu \mathrm{L}$ by rotary evaporation and under a gentle stream of nitrogen gas. Before injection, ${ }^{13} \mathrm{C}_{10^{-}}$ labeled PCN recovery standards (CN64) were added to each of the concentrated extracts.

The target PCNs were analyzed by a gas chromatograph (GC) coupled with a DFS mass spectrometer (Thermo Fisher Scientific, Hudson, NH, USA) using an electron impact (EI) source. A DB-5 MS capillary column $(60 \mathrm{~m} \times 0.25 \mathrm{~mm} \times 0.25 \mu \mathrm{m}$, Agilent Technologies, Santa Clara, CA, USA) was used to separate the PCN congeners. The electron energy was set to $45 \mathrm{eV}$. The source temperature was $270{ }^{\circ} \mathrm{C}$. The high-resolution mass spectrometer was operated in selected ion monitoring mode with a resolution greater than 10,000 . The GC oven program was as follows: held at $80{ }^{\circ} \mathrm{C}$ for $2 \mathrm{~min}$, increased at a rate of $20{ }^{\circ} \mathrm{C} / \mathrm{min}$ to $180{ }^{\circ} \mathrm{C}$ (held $1 \mathrm{~min}$ ), increased at a rate of $2.5^{\circ} \mathrm{C} / \mathrm{min}$ to $280^{\circ} \mathrm{C}$, and increased at a rate of $10^{\circ} \mathrm{C} / \mathrm{min}$ to $290^{\circ} \mathrm{C}$ (held $5 \mathrm{~min}$ ). The injector and interface temperatures were set to $260{ }^{\circ} \mathrm{C}$ and $290{ }^{\circ} \mathrm{C}$, respectively. The carrier gas was helium at a flow rate of $1 \mathrm{~mL} / \mathrm{min}$. The sample size was $1 \mu \mathrm{L}$ and samples were injected in split-less mode. Peaks corresponding to the individual PCN congeners were identified based on their retention times relative to those of internal standards and by their ion ratios. 


\subsection{Quality assurance/quality control}

The recoveries of PCN internal standards ranged from 37 to $117 \%$. The limits of detection (LOD) were calculated using a signal-tonoise ratio of 3:1. The LOD of PCNs ranged from 0.081 to $3.12 \mathrm{fg} /$ $\mathrm{m}^{3}$. In our study, less than $5 \%$ of the data was below LOD (as shown in SI Table S3-S8). The common substitution of "0, 1/2 LOD, LOD $/ \sqrt{2}$ and LOD" were used to calculate the undetected values, which verified substitution of $1 / 2$ LOD has little difference with other values (as shown in SI Table S9-S10). So concentrations of PCNs below the LOD were assigned values equal to half the LOD.

As a quality control measure, field blanks and laboratory blanks were analyzed. The field blanks taken at the sampling site consisted of QFFs and PUFs. They were spiked with the same amount of internal standard as the samples. No difference was found between the concentrations in the field and laboratory blanks and the concentrations were all below LOD.

\section{Results and discussion}

\subsection{PM mass concentrations and size distributions}

Mass concentrations of total suspended particles (TSP) at the sampling site ranged from 119 to $362 \mu \mathrm{g} / \mathrm{m}^{3}$ (mean $234 \mu \mathrm{g} / \mathrm{m}^{3}$ ) (SI Fig. S1). The average concentrations of $\mathrm{PM}_{10}$ and $\mathrm{PM}_{2.5}$ were 209 and $180 \mu \mathrm{g} / \mathrm{m}^{3}$, respectively. The average $\mathrm{PM}_{2.5}$ concentration in this study was 5.14 times higher than the new annual standard of $35 \mu \mathrm{g} / \mathrm{m}^{3}$ set by China's National Ambient Air Quality Standards (Chang, 2012). Many studies have identified PM pollution in the atmosphere (Table 1). The mass concentrations of PM determined in this study were almost at the same level as those measured in earlier studies in Beijing, China (Zhao et al., 2005), Guangzhou, China (Duan et al., 2007), and some Indian cities (Sharma and Maloo, 2005). However, the PM mass concentrations in this study were much higher than those reported in Shanghai, China (Ma et al., 2013), the Czech Republic (Okonski et al., 2014), Nagoya, Japan (Kadowaki and Naitoh, 2005), Western Europe and North America (Sharma and Maloo, 2005) and Illmitz, Austria (Barmpadimos et al., 2012).

More of the PM was present in the smaller size fractions than the larger size fractions (Fig. 1). The PM fraction with particle diameters $\leq 1.0 \mu \mathrm{m}$ was the most abundant fraction and contributed nearly $63.5 \%$ of the total PM mass. The finding that the majority of $\mathrm{PM}$ was in the fine particle range is in agreement with an earlier study where outdoor aerosols contained mostly fine particles $\left(\mathrm{d}_{\mathrm{ae}} \leq 2.5 \mu \mathrm{m}\right.$, especially $\left.\mathrm{d}_{\mathrm{ae}} \leq 1.0 \mu \mathrm{m}\right)$ (Vette et al., 2001).

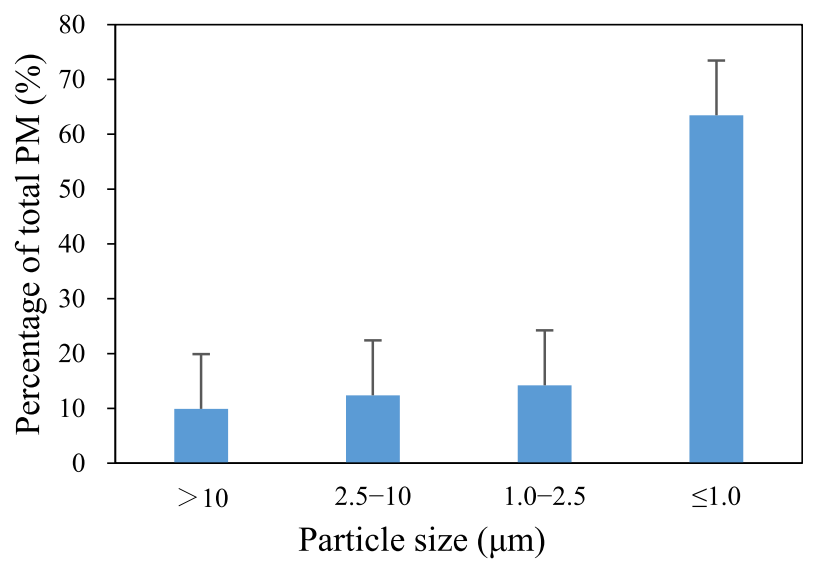

Fig. 1. Size distribution of particulate matter.

\subsection{Concentrations of PCNs in the atmosphere}

In this study, tetra- to octachloro-CNs were analyzed. The $\Sigma$ PCNs is the sum of the concentrations of the 49 individual PCN congeners that were detected in the air samples. Atmospheric concentrations (gas + particle fractions) of $\Sigma$ PCNs in the urban atmosphere ranged from 6.77 to $25.90 \mathrm{pg} / \mathrm{m}^{3}$ (Fig. 2) and the range of particle-bound concentrations was $0.17-2.78 \mathrm{pg} / \mathrm{m}^{3}$. The total concentration of PCNs in sample F (sample details are provided in SI Table S2) was lower than that in any of the other samples collected and it is possible that this sample was affected by rain that fell during

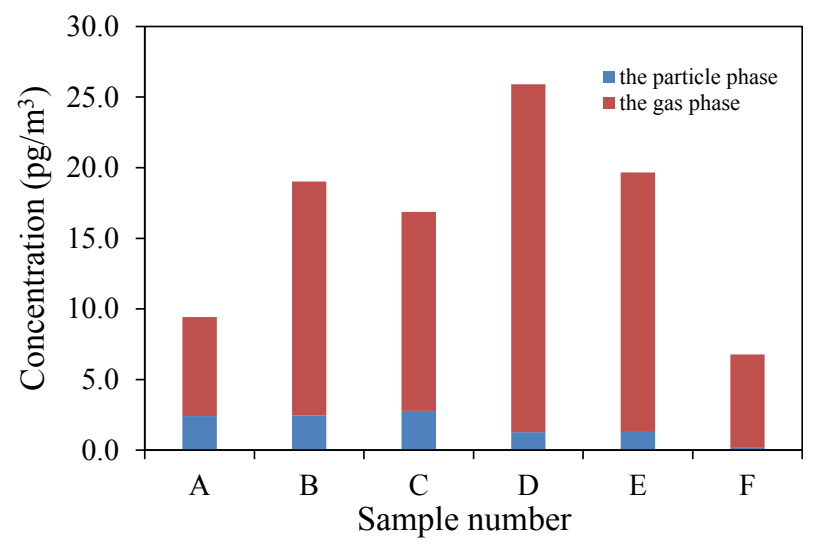

Fig. 2. Concentrations of PCNs in the particle phase and gas phase.

Table 1

Particulate matter mass concentrations in different regions (unit $\mu \mathrm{g} / \mathrm{m}^{3}$ ).

\begin{tabular}{|c|c|c|c|c|}
\hline Region & Sampling period & Particle range & Concentration $\left(\mu \mathrm{g} / \mathrm{m}^{3}\right)$ & References \\
\hline Beijing, China & 2005 & $\mathrm{PM}_{10}$ & 179.8 & (Zhao et al., 2005) \\
\hline Guangzhou, China & $2003-2004$ & $\mathrm{PM}_{10}$ & $80-397$ & (Duan et al., 2007) \\
\hline \multirow[t]{2}{*}{ Kanpur, India } & \multirow[t]{2}{*}{$2002-2003$} & $\mathrm{PM}_{10}$ & $45-589$ & \multirow{2}{*}{ (Sharma and Maloo, 2005) } \\
\hline & & $\mathrm{PM}_{2.5}$ & $25-200$ & \\
\hline \multirow[t]{2}{*}{ Czech Republic } & \multirow[t]{2}{*}{$2009-2010$} & \multirow[t]{2}{*}{$\mathrm{PM}_{10}$} & $5.08-90.5$ (rural site) & \multirow[t]{2}{*}{ (Okonski et al., 2014) } \\
\hline & & & $16.1-78.0$ (urban site) & \\
\hline \multirow[t]{2}{*}{ Shanghai, China } & \multirow[t]{2}{*}{ 2011-2012 } & $\mathrm{PM}_{10}$ & 150 & \multirow[t]{2}{*}{ (Ma et al., 2013) } \\
\hline & & $\mathrm{PM}_{2.5}$ & 90.5 & \\
\hline NAAQS & - & $\mathrm{PM}_{2.5}$ & 35 & (Chang, 2012) \\
\hline the U.S. annual health standard & - & $\mathrm{PM}_{2.5}$ & 12 & (Ma et al., 2013) \\
\hline Nagoya, Japan & $2000-2001$ & TSP & $55-160$ & (Kadowaki and Naitoh, 2005) \\
\hline Western Europe and North America & - & $\mathrm{PM}_{10}$ & $10-55$ & (Sharma and Maloo, 2005) \\
\hline \multirow[t]{2}{*}{ Illmitz, Austria } & \multirow[t]{2}{*}{$2001-2010$} & $\mathrm{PM}_{10}$ & 25 & \multirow[t]{2}{*}{ (Barmpadimos et al., 2012) } \\
\hline & & $\mathrm{PM}_{2.5}$ & 20 & \\
\hline \multirow[t]{2}{*}{ Beijing, China } & \multirow[t]{2}{*}{$2013-2014$} & $\mathrm{PM}_{10}$ & 209 & This study \\
\hline & & $\mathrm{PM}_{2.5}$ & 180 & This study \\
\hline
\end{tabular}


sampling. Therefore, wet deposition may help to remove contaminants from the atmosphere. Principal components analysis (PCA) (SI Fig. S2) identified notable PCN combustion markers such as CN52/60, -50, -51, -54, -49 and -66/67 (Falandysz, 1998; Hogarh et al., 2012a; Lee et al., 2007; Liu et al., 2015; Noma et al., 2006). This suggested that combustion emerged certain contribution to the measured PCN concentrations. Some earlier studies have reported PCN concentrations in the atmosphere (Hogarh et al., 2012a,b). Because the concentrations of PCNs vary with the type of air samples (e.g., gas phase, particle phase, or both) and the numbers of identified compounds, it is difficult to directly compare the concentrations of PCNs measured in different studies. A rough comparison suggested that $\mathrm{PCN}$ concentrations in Beijing during this study were comparable to, or slightly lower than, concentrations measured during other studies, as shown in Table 2. PCN concentrations in the gas phase ranged from 6.60 to $24.63 \mathrm{pg} / \mathrm{m}^{3}$ and were on average 8.41 times higher than those in the particle phase $\left(0.17-2.78 \mathrm{pg} / \mathrm{m}^{3}\right)$. Because they are semi-volatile organic compounds, most PCNs have relatively high volatilities and can easily evaporate from various matrices. Volatilization is an important migration pathway for PCNs to the atmosphere, and especially for transferring from the particle phase to the gas phase. The high volatilities of PCNs certainly contribute to their high abundances in the gas phase. The high contribution of gas phase PCNs to the total PCNs (almost 88.5\%) in the atmosphere agrees with the results reported by Odabasi et al. (2012) (33-94\%) and Gregoris et al. (2014) (95.7\%).

The effect of temperature on the gas/particle partitioning of PCNs was also evaluated (SI Fig. S3). The correlation analyses of temperature with the concentrations of $\Sigma \mathrm{PCN}$ s were conducted using the SPSS Statistics 20 software. The Pearson rank correlation coefficients are listed in SI Table S11. Table S11 shows that the concentrations of $\Sigma \mathrm{PCN}$ in the gas fraction had little correlation with the temperature. The ratio of $\Sigma P C N s$ in the gas fraction to $\Sigma$ PCNs in total fractions (gas + particle fractions) showed a small positive correlation (0.643) with temperature. This suggested that the relationship between temperature and the gas/particle partitioning of PCNs in urban air was not significant.

\subsection{Size-specific distributions of PCNs in PM fractions}

Four airborne PM fractions with different diameters were collected. The total concentrations of the PCNs in the different fractions are presented in Fig. 3. The mean and median concentrations of $\Sigma$ PCNs in the TSP were 1.73 and $1.85 \mathrm{pg} / \mathrm{m}^{3}$, respectively, with a range of $0.169-2.78 \mathrm{pg} / \mathrm{m}^{3}$. The mean and median concentrations of $\Sigma \mathrm{PCNs}$ in $\mathrm{PM}_{10}$ were 1.65 and $1.77 \mathrm{pg} / \mathrm{m}^{3}$, respectively, with a range of $0.157-2.65 \mathrm{pg} / \mathrm{m}^{3}$. For $\mathrm{PM}_{2.5}$, the mean and median

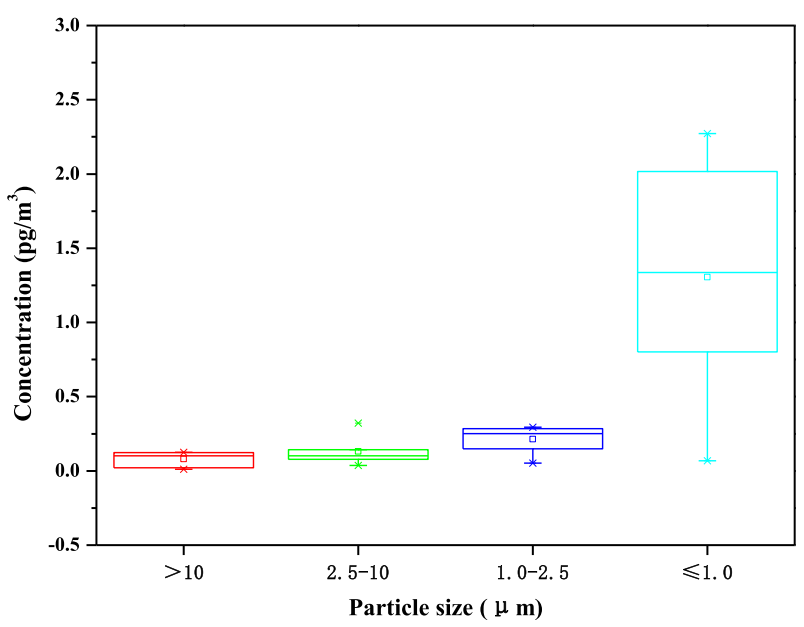

Fig. 3. Distribution of $\mathrm{PCNs}$ in different particulate matter fractions.

concentrations of $\Sigma P C N s$ were 1.52 and $1.55 \mathrm{pg} / \mathrm{m}^{3}$, respectively, with a range of $0.12-2.51 \mathrm{pg} / \mathrm{m}^{3}$. For $\mathrm{PM}_{1.0}$, the mean and median concentrations of $\Sigma$ PCNs were 1.30 and $1.34 \mathrm{pg} / \mathrm{m}^{3}$, respectively, with a range of $0.0676-2.27 \mathrm{pg} / \mathrm{m}^{3}$. The concentration of PCNs in $\mathrm{PM}_{2.5}$ was comparable to that in TSP. This highlighted that fine particles were the main contributors (70.7-95.9\%) to the TSP. For the toxic equivalency (TEQ) of PCNs in $\mathrm{PM}, \mathrm{PM}_{2.5}$ was also the main contributor, accounting for $77.3-98.5 \%$ of the TSP, as shown in Fig. $4 \mathrm{a}$ and $4 \mathrm{~b}$.

The distribution patterns of organic pollutants in airborne particles (Ni and Zeng, 2013; Okonski et al., 2014) or dust (Cao et al., 2014; Wang et al., 2013a,b) have raised concern recently. However, to date, there has been no research on the size-specific distributions of PCNs in PM fractions in the atmosphere. Earlier studies have reported the particle size distributions of other pollutants, including $\mathrm{PCDD} / \mathrm{Fs}$, PCBs, organochlorine pesticides, PAHs and brominated flame retardants. The distributions of these chemicals generally varied with particle size, and they also depended on the type of chemical. For example, HBCD and TBBPA tended to be present in the fraction of $0.4-2.2 \mu \mathrm{m}$ rather than the fraction of $2.5-8.9 \mu \mathrm{m}$ in office air (Ni and Zeng, 2013). The size-specific distributions of polybrominated diphenyl ether featured a distinct enrichment in smaller particles, with $>46 \%$ of polybrominated diphenyl ether associated with particles $<0.57 \mu \mathrm{m}$ in diameter in urban air (Mandalakis et al., 2009). PAHs were mainly associated with the smallest particle sizes $(<0.4 \mu \mathrm{m})$ among nine fractions of atmospheric PM collected at a roadside (Hien et al., 2007). Similarly, PCBs predominantly tended to be present in the smallest

Table 2

$\mathrm{PCN}$ concentrations in different regions (unit $\mathrm{pg} / \mathrm{m}^{3}$ ).

\begin{tabular}{|c|c|c|c|c|c|c|}
\hline Region & Year & Sampling method & Type of air samples & Identified PCN numbers & Concentration $\left(\mathrm{pg} / \mathrm{m}^{3}\right)$ & References \\
\hline The north-south Atlantic transect & 2001 & $\mathrm{AAS}^{\mathrm{a}}$ & gas + particle phase & 13 & $0.3-86$ & (Jaward et al., 2004) \\
\hline Izmir, Turkey & $2004-2005$ & PAS $^{b}$ & gas phase & 32 & $\begin{array}{l}5.2-162 \text { (summer) } \\
3.7-229 \text { (winter) }\end{array}$ & (Odabasi et al., 2012) \\
\hline Japan & 2008 & PAS & gas phase & 63 & $9.5 \pm 1.5$ & (Hogarh et al., 2012a) \\
\hline China & & & & & $61 \pm 6$ & \\
\hline Korea & & & & & $16 \pm 2.4$ & \\
\hline The Pearl River Basin, China & 2010 & PAS & gas phase & 36 & $6.4-832$ & (Wang et al., 2012) \\
\hline Ghana & 2010 & PAS & gas phase & 63 & $27-95$ & (Hogarh et al., 2012b) \\
\hline \multirow[t]{2}{*}{ Venice } & 2009 & AAS & gas + particle phase & 6 & 89 & (Gregoris et al., 2014) \\
\hline & 2012 & & & & 0.29 & \\
\hline Beijing, China & $2013-2014$ & AAS & gas + particle phase & 49 & $6.77-25.90$ & This study \\
\hline
\end{tabular}

a AAS = active air sampler.

b $\mathrm{PAS}=$ passive air sampler. 

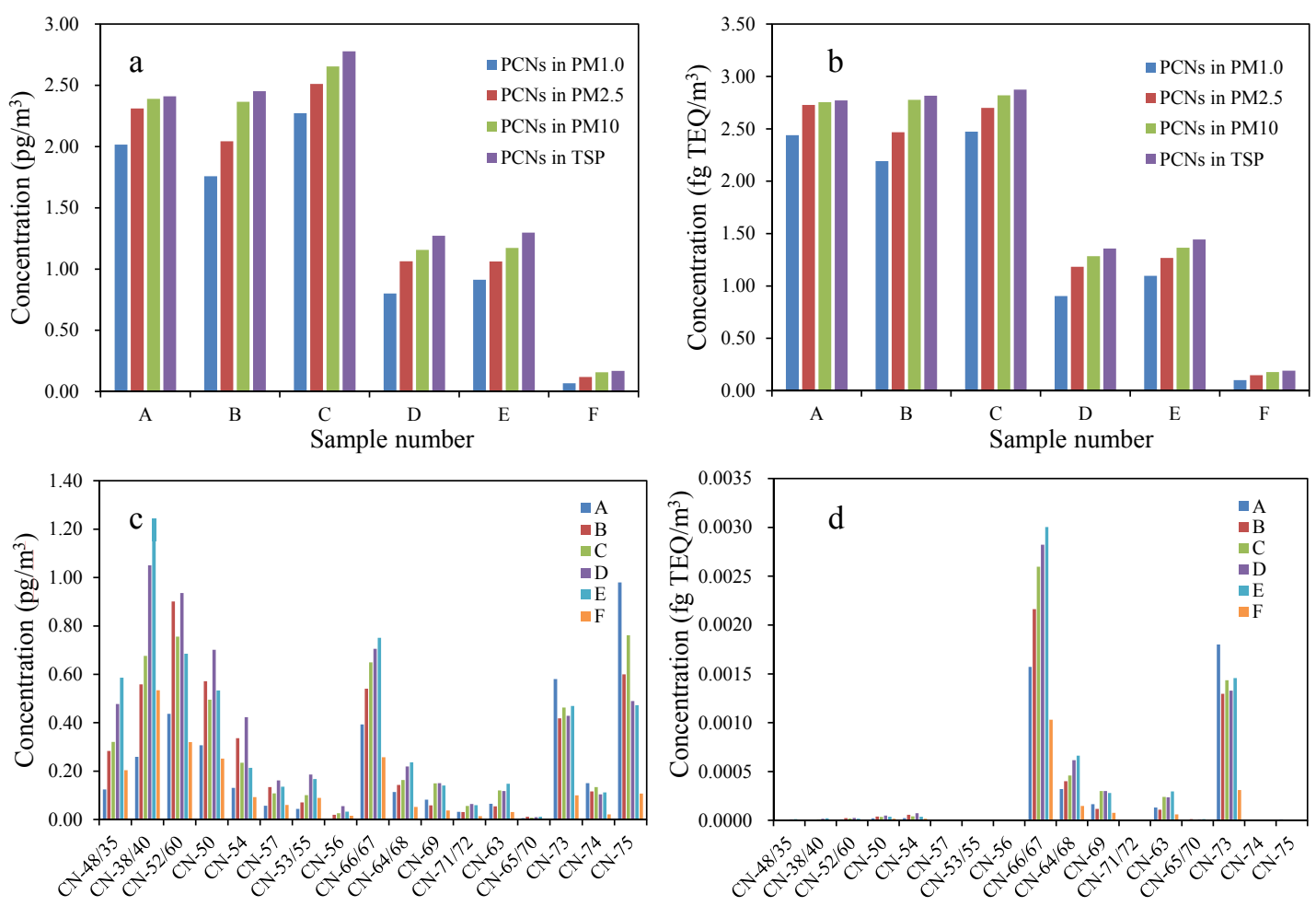

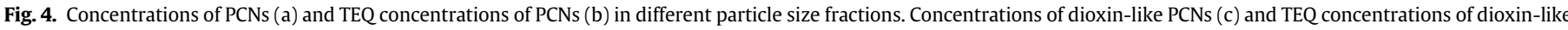
PCNs (d) in the atmosphere (gas + particle fractions).

fraction $\left(\mathrm{d}_{\mathrm{ae}}<0.95 \mu \mathrm{m}\right)$ among five fractions collected from trafficimpacted outdoor air (Chrysikou et al., 2009).

In agreement with these studies, our study found large differences in the distributions of $\Sigma$ PCNs among the PM fractions. The PCN concentrations in each PM fraction increased as the particle size decreased $\left(\mathrm{d}_{\mathrm{ae}}>10 \mu \mathrm{m}, 10 \mu \mathrm{m} \geq \mathrm{d}_{\mathrm{ae}}>2.5 \mu \mathrm{m}\right.$, $2.5 \mu \mathrm{m} \geq \mathrm{d}_{\mathrm{ae}}>1.0 \mu \mathrm{m}$ and $\left.\mathrm{d}_{\mathrm{ae}} \leq 1.0 \mu \mathrm{m}\right)$, and the $\Sigma \mathrm{PCNs}$ associated with particles $\leq 2.5 \mu \mathrm{m}$ in diameter was high (range 70.7-95.9\%, mean $84.3 \%$ ). These results showed that fine particles contained higher concentrations of PCNs. This suggests that $\Sigma$ PCNs may tend to adsorb onto finer PM. For the partitioning of organic pollutants between particles of different sizes, the absorption capacity of the particles is proportional to the organic content and surface area, which means that fine particles have higher mass transfer rates than larger particles (Li and Davis, 1996; Liu et al., 2013). Therefore, the enrichment of PCNs on fine particles $\left(\mathrm{PM}_{1.0}\right.$ or $\left.\mathrm{PM}_{2.5}\right)$ could be attributed to their larger surface areas compared with larger particles.

\subsection{Homologue composition and fractionation}

SI Fig. S4 summarizes the profiles of the PCNs (gas + particle fractions) obtained in this study. From Fig. S4 it is evident that tetra$\mathrm{CNs}$ and penta-CNs, which are lower chlorinated homologues, predominated. In this study, these two homologues accounted for approximately $86.5 \%$ of total PCNs. By comparison, lower chlorinated homologues (tri-CNs and tetra-CNs) accounted for approximately $80 \%$ of total PCNs in East Asian countries (Hogarh et al., 2012a) and approximately 90\% in Ghana (Hogarh et al., 2012b). The large contribution of lower chlorinated homologues in the atmosphere in Beijing could be attributed to the high saturation vapor pressures of PCNs, which was similar to PCBs because of their similar properties (Li et al., 2010).
The PCN profiles in the different size particles were almost similar (SI Fig. S5), but as the particle size decreased, the contribution of higher chlorinated homologues increased. For example, in the $\leq 1.0 \mu \mathrm{m}$ fraction, the contributions were in the order: octa$\mathrm{CN}>$ hepta-CNs $>$ hexa-CNs $>$ tetra-CNs $>$ penta-CNs. By comparison, in the $>10 \mu \mathrm{m}$ fraction, the contributions were in the order: tetra-CNs $>$ octa-CN $>$ hepta-CNs $>$ penta-CNs $>$ hexa-CNs. Finer particles could adsorb more of the less volatile pollutants than larger particles. This further verified that the fine particles are more enriched with PCNs than larger particles. In addition, the homologue profiles were clearly different in the particle and gas phases (SI Fig. S5). In the particle phase, octa-CN was the main contributor, while tetra-CNs predominated in the gas phase and contributed approximately $79.2 \%$ of the total PCNs. The homologue profiles in the gas and particle phases were reversed.

With regard to the toxicity, 17 PCN congeners with known toxic equivalency factors (TEFs) were used to assess the overall PCN TEQ in this study (Fig. 4d). The TEQs of PCNs were estimated as $\sum_{n=1}^{17} C_{n} \times \mathrm{TEF}_{n}$, where $\mathrm{C}_{n}$ and $\mathrm{TEF}_{n}$ are the PCN concentrations and TEF of the $n$th congener, respectively. The TEFs are listed in SI Table S12. Because PCNs act through a similar mechanism to dioxins, the TEFs of PCNs were determined by comparing their toxicity to that of the most toxic dioxin 2,3,7,8-TCDD, which is assigned a TEF of 1 (Hogarh et al., 2012b). Here, the dominant toxic congeners were CN66/67 and CN73, which showed relatively high TEFs compared with the other PCN congeners. Moreover, CN38/40, CN52/60 and CN75 were the dominant PCN congeners in all samples, accounting for $39.4-44.5 \%$ of the total concentration of dioxin-like PCNs (dl-PCNs).

\subsection{Preliminary assessment of exposure to PCNs via inhalation}

Environmental exposure to PCNs for humans was calculated for 
Table 3

Evaluation of the inhalation risk from PCNs in Beijing, China.

\begin{tabular}{llll}
\hline Sample number & TEQ of inhalable fractions $\left(\mathrm{fg} \mathrm{TEQ} / \mathrm{m}^{3}\right)$ & $\begin{array}{l}\mathrm{PCN} \text { inhalation } \\
(\mathrm{fg} \mathrm{TEQ} / \mathrm{kg} / \mathrm{d})\end{array}$ \\
\cline { 3 - 4 } & & Adult & Children \\
\hline A & 4.05 & 0.87 & 1.54 \\
$\mathrm{~B}$ & 4.20 & 0.90 & 1.60 \\
$\mathrm{C}$ & 5.11 & 1.09 & 1.94 \\
D & 5.43 & 1.16 & 2.06 \\
E & 5.77 & 1.24 & 2.19 \\
F & 1.67 & 0.36 & 0.64 \\
Arithmetic mean & 4.37 & 0.94 & 1.66 \\
\hline
\end{tabular}

the main exposure pathways of dietary ingestion, dermal absorption and inhalation. For atmospheric pollutants, inhalation and dermal absorption are more important than dietary ingestion. Daily inhalation exposure doses of PCNs for adults and children were calculated with reference to calculation for dioxins (SI Eq. (1)) (Nouwen et al., 2001).

PCN concentrations in the inhalable particles $\left(\mathrm{PM}_{10}\right)$ fraction and gas fraction were used to calculate the daily PCNs inhalation exposure. The results are summarized in Table 3 . The results showed that residents in the sample collection area were at risk of exposure to PCNs, with an average inhalation of $0.94 \mathrm{fg} \mathrm{TEQ} / \mathrm{kg} /$ $\mathrm{d}$ for adults and $1.66 \mathrm{fg} \mathrm{TEQ} / \mathrm{kg} / \mathrm{d}$ for children. Compared with previous studies, these results were similar to those in Ghana (Hogarh et al., 2012b) and much lower than areas near municipal solid waste incinerators in Spain (Vilavert et al., 2014). Furthermore, children are at a much higher risk of PCN exposure than adults, and that they are the main victims of poor air quality.

The World Health Organization (WHO) specifies a tolerable daily intake (TDI) for dioxins of $1-4 \mathrm{pg}$ TEQ $/ \mathrm{kg} / \mathrm{d}$ (Van Leeuwen et al., 2000). For an adult weighing $60 \mathrm{~kg}$, the maximum WHOTDI for dioxins is estimated as $240 \mathrm{pg}$ TEQ/d (4 pg TEQ/kg/ $\mathrm{d} \times 60 \mathrm{~kg}$ ). We estimated that daily exposure to the highest dioxinlike toxicity from PCNs in urban air might account for approximately $0.03 \%$ of the maximum WHO-TDI for dioxin toxicity. Based on our results for inhalation, we can infer that the TDIs for residents in Beijing are low. Although the contribution of dioxin-like toxicity from PCNs in the air was low, there are other routes of exposure, such as through food and water, and other dioxin-like compounds in these media should be monitored to evaluate the total dioxinrelated burden in Beijing.

\section{Conclusion}

In this study, the concentrations and size-specific distributions of $49 \mathrm{PCN}$ congeners were investigated in Beijing and used to conduct a preliminary exposure assessment. The atmospheric $\Sigma$ PCNs concentrations (gas + particle) varied from 6.77 to $25.90 \mathrm{pg} /$ $\mathrm{m}^{3}$, and were comparable to, or slightly lower than, those reported in other regions. Overall, PCNs mainly tended to be in the gas phase, which was consistent with earlier studies.

To the best of our knowledge, this is the first study to investigate the distribution of PCNs in different particle size fractions in the atmosphere. The PM mass concentrations and PCN concentrations were highest in the $\leq 1.0 \mu \mathrm{m}$ fraction. $\Sigma$ PCNs associated with $\mathrm{PM}_{1.0}$ and $\mathrm{PM}_{2.5}$ reached $68.4 \%$ and $84.3 \%$, respectively. The lower chlorinated homologues, tetra-CNs and penta-CNs, predominated in the atmosphere. The homologue profiles in different size particles were similar, but different to that in the gas phase. Also, the particle size distributions of PCNs affected their potential impact on human health. Further research is necessary to assess whether long-term inhalation exposure to $\mathrm{PCNs}$ associated with $\mathrm{PM}_{1.0}$ or $\mathrm{PM}_{2.5}$ in urban areas poses a significant threat to human health.

\section{Acknowledgments}

This study was financially supported by the National Natural Science Foundation of China (Nos. 21361140359 and 21321004), the National 973 project (No. 2015CB453100) and the Strategic Priority Research Program of the Chinese Academy of Sciences (No. XDB14020000).

\section{Appendix A. Supplementary data}

Supplementary data related to this article can be found at http:// dx.doi.org/10.1016/j.envpol.2016.01.065.

\section{References}

Aulinger, A., Matthias, V., Quante, M., 2007. Introducing a partitioning mechanism for PAHs into the community multiscale air quality modeling system and its application to simulating the transport of benzo (a) pyrene over Europe. J. Appl. Meteor. Climatol. 46, 1718-1730.

Barmpadimos, I., Keller, J., Oderbolz, D., Hueglin, C., Prévôt, A., 2012. One decade of parallel fine $\left(\mathrm{PM}_{2.5}\right)$ and coarse $\left(\mathrm{PM}_{10}-\mathrm{PM}_{2.5}\right)$ particulate matter measurements in Europe: trends and variability. Atmos. Chem. Phys. 12, 3189-3203.

Bi, X., Sheng, G., Peng, P., Chen, Y., Fu, J., 2005. Size distribution of n-alkanes and polycyclic aromatic hydrocarbons (PAHs) in urban and rural atmospheres of Guangzhou, China. Atmos. Environ. 39, 477-487.

Bidleman, T.F., 1988. Atmospheric processes-wet and dry deposition of organic compounds are controlled by their vapor-particle partitioning. Environ. Sci. Technol. 22, 361-367.

Bidleman, T.F., Helm, P.A., Braune, B.M., Gabrielsen, G.W., 2010. Polychlorinated naphthalenes in polar environments-a review. Sci. Total. Environ. 408, 2919-2935.

Brunekreef, B., Forsberg, B., 2005. Epidemiological evidence of effects of coarse airborne particles on health. Eur. Respir. J. 26, 309-318.

Cao, Z., Xu, F., Covaci, A., Wu, M., Wang, H., Yu, G., Wang, B., Deng, S., Huang, J., Wang, X., 2014. Distribution patterns of brominated, chlorinated, and phosphorus flame retardants with particle size in indoor and outdoor dust and implications for human exposure. Environ. Sci. Technol. 48, 8839-8846.

Chang, Y., 2012. China needs a tighter $\mathrm{PM}_{2.5}$ limit and a change in priorities. Environ. Sci. Technol. 46, 7069-7070.

Chao, M., Hu, C., Ma, H., Chang-Chien, G., Lee, W., Chang, L.W., Wu, K., 2003. Size distribution of particle-bound polychlorinated dibenzo-p-dioxins and dibenzofurans in the ambient air of a municipal incinerator. Atmos. Environ. 37, 4945-4954.

Chen, R., Kan, H., Chen, B., Huang, W., Bai, Z., Song, G., Pan, G., 2012. Association of particulate air pollution with daily mortality the China air pollution and health effects study. Am. J. Epidemiol. 175, 1173-1181.

Chrysikou, L.P., Gemenetzis, P.G., Samara, C.A., 2009. Wintertime size distribution of polycyclic aromatic hydrocarbons (PAHs), polychlorinated biphenyls (PCBs) and organochlorine pesticides (OCPs) in the urban environment: street- vs rooftoplevel measurements. Atmos. Environ. 43, 290-300.

Chrysikou, L.P., Samara, C.A., 2009. Seasonal variation of the size distribution of urban particulate matter and associated organic pollutants in the ambient air. Atmos. Environ. 43, 4557-4569.

Chuang, K.Y., Lai, C.H., Peng, Y.P. Yen, TY, 2015. Characteristics of particle-bound polychlorinated dibenzo-p-dioxins and dibenzofurans (PCDD/Fs) in atmosphere used in carbon black feeding process at a tire manufacturing plant. Environ. Sci. Pollut. Res. 22, 19451-19460.

Coscollà, C., Yahyaoui, A., Colin, P., Robin, C., Martinon, L., Val, S., Baeza-Squiban, A. Mellouki, A., Yusà, V., 2013. Particle size distributions of currently used pesticides in a rural atmosphere of France. Atmos. Environ. 81, 32-38.

Dominici, F., Peng, R.D., Bell, M.L., Pham, L., McDermott, A., Zeger, S.L., Samet, J.M. 2006. Fine particulate air pollution and hospital admission for cardiovascular and respiratory diseases. J. Am. Med. Assoc. 295, 1127-1134.

Duan, J., Bi, X., Tan, J., Sheng, G., Fu, J., 2007. Seasonal variation on size distribution and concentration of PAHs in Guangzhou city, China. Chemosphere 67, 614-622.

Falandysz, J., 1998. Polychlorinated naphthalenes: an environmental update. Environ. Pollut. 101, 77-90.

Fromme, H., Cequier, E., Kim, J.T., Hanssen, L., Hilger, B., Thomsen, C., Chang, Y.S., Völkel, W., 2015. Persistent and emerging pollutants in the blood of German adults: occurrence of dechloranes, polychlorinated naphthalenes, and siloxanes. Environ. Int. 85, 292-298.

Gregoris, E., Argiriadis, E., Vecchiato, M., Zambon, S., De Pieri, S., Donateo, A., Contini, D., Piazza, R., Barbante, C., Gambaro, A., 2014. Gas-particle distributions, sources and health effects of polycyclic aromatic hydrocarbons (PAHs), polychlorinated biphenyls (PCBs) and polychlorinated naphthalenes (PCNs) in Venice aerosols. Sci. Total. Environ. 476, 393-405.

Harner, T., Bidleman, T.F., 1998. Octanol-air partition coefficient for describing 
particle/gas partitioning of aromatic compounds in urban air. Environ. Sci. Technol. 32, 1494-1502.

Harner, T., Shoeib, M., Gouin, T., Blanchard, P., 2006. Polychlorinated naphthalenes in Great Lakes air: assessing spatial trends and combustion inputs using PUF disk passive air samplers. Environ. Sci. Technol. 40, 5333-5339.

Helm, P.A., Gewurtz, S.B., Whittle, D.M., Marvin, C.H., Fisk, A.T., Tomy, G.T., 2008 Occurrence and biomagnification of polychlorinated naphthalenes and non-and mono-ortho PCBs in Lake Ontario sediment and biota. Environ. Sci. Technol. 42, 1024-1031.

Hien, T.T., Kameda, T., Takenaka, N., Bandow, H., 2007. Distribution characteristics of polycyclic aromatic hydrocarbons with particle size in urban aerosols at the roadside in Ho Chi Minh City, Vietnam. Atmos. Environ. 41, 1575-1586.

Hogarh, J.N., Seike, N., Kobara, Y., Habib, A., Nam, J.J., Lee, J.S., Li, Q.L., Liu, X., Li, J., Zhang, G., Masunaga, S., 2012a. Passive air monitoring of PCBs and PCNs across East Asia: a comprehensive congener evaluation for source characterization. Chemosphere 86, 718-726.

Hogarh, J.N., Seike, N., Kobara, Y., Masunaga, S., 2012b. Atmospheric polychlorinated naphthalenes in Ghana. Environ. Sci. Technol. 46, 2600-2606.

Jiang, X., Liu, G., Wang, M., Zheng, M., 2015. Fly ash-mediated formation of polychlorinated naphthalenes during secondary copper smelting and mechanistic aspects. Chemosphere 119, 1091-1098.

Jaward, F.M., Barber, J.L., Booij, K., Jones, K.C., 2004. Spatial distribution of atmospheric PAHs and PCNs along a north-south Atlantic transect. Environ. Pollut $132,173-181$.

Kadowaki, S., Naitoh, H., 2005. Gas-particle partitioning of PCDD/Fs in Nagoya urban air, Japan. Chemosphere 59, 1439-1453.

Kaupp, H., McLachlan, M.S., 2000. Distribution of polychlorinated dibenzo-pdioxins and dibenzofurans (PCDD/Fs) and polycyclic aromatic hydrocarbons (PAHs) within the full size range of atmospheric particles. Atmos. Environ. 34, 73-83.

Kurokawa, Y., Takahiko, M., Matayoshi, N., Satoshi, T., FKazumi, F., 1998. Distribution of polychlorinated dibenzo-p-dioxins and dibenzofurans in various sizes of airborne particles. Chemosphere 37, 2161-2171.

Lee, S.C., Harner, T., Pozo, K., Shoeib, M., Wania, F., Muir, D.C., Barrie, L.A., Jones, K.C., 2007. Polychlorinated naphthalenes in the global atmospheric passive sampling (GAPS) study. Environ. Sci. Technol. 41, 2680-2687.

Li, Q., Xu, Y., Li, J., Pan, X., Liu, X., Zhang, G., 2012. Levels and spatial distribution of gaseous polychlorinated biphenyls and polychlorinated naphthalenes in the air over the northern South China Sea. Atmos. Environ. 56, 228-235.

Li, W.G., Davis, E.J., 1996. Aerosol evaporation in the transition regime. Aerosol Sci. Technol. 25, 11-21.

Li, Y.F., Harner, T., Liu, L., Zhang, Z., Ren, N.Q., Jia, H., Ma, J., Sverko, E., 2010. Polychlorinated biphenyls in global air and surface soil: distributions, air-soil exchange, and fractionation effect. Environ. Sci. Technol. 44, 2784-2790.

Liu, C., Shi, S.S., Weschler, C., Zhao, B., Zhang, Y.P., 2013. Analysis of the dynamic interaction between SVOCs and airborne particles. Aerosol Sci. Technol. 47, $125-136$.

Liu, G., Cai, Z., Zheng, M., 2014. Sources of unintentionally produced polychlorinated naphthalenes. Chemosphere 94, 1-12.

Liu, G., Cai, Z., Zheng, M., Jiang, X., Nie, Z., Wang, M., 2015. Identification of indicator congeners and evaluation of emission pattern of polychlorinated naphthalenes in industrial stack gas emissions by statistical analyses. Chemosphere 118, 194-200.

Liu, G., Zheng, M., Lv, P., Liu, W., Wang, C., Zhang, B., Xiao, K., 2010. Estimation and characterization of polychlorinated naphthalene emission from coking industries. Environ. Sci. Technol. 44, 8156-8161.

Ma, J., Chen, Z., Wu, M., Feng, J., Horii, Y., Ohura, T., Kannan, K., 2013. Airborne PM$_{2.5}$ $\mathrm{PM}_{10}$-associated chlorinated polycyclic aromatic hydrocarbons and their parent compounds in a suburban area in Shanghai, China. Environ. Sci. Technol. 47, 7615-7623.

Mandalakis, M., Besis, A., Stephanou, E.G., 2009. Particle-size distribution and gas/ particle partitioning of atmospheric polybrominated diphenyl ethers in urban areas of Greece. Environ. Pollut. 157, 1227-1233.

Meng, X., Ma, Y., Chen, R., Zhou, Z., Chen, B., Kan, H., 2013. Size-fractionated particle number concentrations and daily mortality in a Chinese city. Environ. Health Perspect. 121, 1174-1178.

Ni, H., Zeng, H., 2013. HBCD and TBBPA in particulate phase of indoor air in Shenzhen, China. Sci. Total. Environ. 458, 15-19.

Noma, Y., Yamamoto, T., Giraud, R., Sakai, S., 2006. Behavior of PCNs, PCDDs, PCDFs and dioxin-like PCBs in the thermal destruction of wastes containing PCNs. Chemosphere 62, 1183-1195.

Nouwen, J., Cornelis, C., De Fre, R., Wevers, M., Viaene, P., Mensink, C., Patyn, J. Verschaeve, L., Hooghe, R., Maes, A., 2001. Health risk assessment of dioxin emissions from municipal waste incinerators: the Neerlandquarter (Wilrijk, Belgium). Chemosphere 43, 909-923.

Odabasi, M., Bayram, A., Elbir, T., Dumanoglu, Y., Kara, M., Altiok, H., Cetin, B., 2012. Investigation of seasonal variations and sources of atmospheric polychlorinated naphthalenes (PCNs) in an urban area. Atmos. Pollut. Res. 3, 477-484.

Oh, J.E., Chang, Y.S., Kim, E.J., Lee, D.W., 2002. Distribution of polychlorinated dibenzo-p-dioxins and dibenzofurans (PCDD/Fs) in different sizes of airborne particles. Atmos. Environ. 36, 5109-5117.

Okonski, K., Degrendele, C., Melymuk, L., Landlova, L., Kukucka, P., Vojta, S., Kohoutek, J., Cupr, P., Klanova, J., 2014. Particle size distribution of halogenated flame retardants and implications for atmospheric deposition and transport. Environ. Sci. Technol. 48, 14426-14434.

Park, H., Kang, J.H., Baek, S.Y., Chang, Y.S., 2010. Relative importance of polychlorinated naphthalenes compared to dioxins, and polychlorinated biphenyls in human serum from Korea: contribution to TEQs and potential sources. Environ. Pollut. 158, 1420-1427.

Sánchez-Soberón, F., Rovira, J., Mari, M., Sierra, J., Nadal, M., Domingo, J.L., Schuhmacher, M., 2015. Main components and human health risks assessment of $\mathrm{PM}_{10}, \mathrm{PM}_{2.5}$, and $\mathrm{PM}_{1}$ in two areas influenced by cement plants. Atmos. Environ. 120, 109-116.

Sharma, M., Maloo, S., 2005. Assessment of ambient air $\mathrm{PM}_{10}$ and $\mathrm{PM}_{2.5}$ and characterization of $\mathrm{PM}_{10}$ in the city of Kanpur, India. Atmos. Environ. 39, 6015-6026.

Sun, Y., Zhuang, G., Tang, A., Wang, Y., An, Z., 2006. Chemical characteristics of $\mathrm{PM}_{2.5}$ and $\mathrm{PM}_{10}$ in haze-fog episodes in Beijing. Environ. Sci. Technol. 40, 3148-3155.

Valavanidis, A., Fiotakis, K., Vlachogianni, T., 2008. Airborne particulate matter and human health: toxicological assessment and importance of size and composition of particles for oxidative damage and carcinogenic mechanisms. J. Environ. Sci. Health., Part C Environ. Carcinog. Ecotoxicol. Rev. 26, 339-362.

Van Leeuwen, F.R., Feeley, M., Schrenk, D., Larsen, J.C., Farland, W., Younes, M., 2000. Dioxins: WHO's tolerable daily intake (TDI) revisited. Chemosphere 40, 1095-1101.

Vette, A.F., Rea, A.W., Lawless, P.A., Rodes, C.E., Evans, G., Highsmith, V.R., Sheldon, L., 2001. Characterization of indoor-outdoor aerosol concentration relationships during the Fresno PM exposure studies. Aerosol Sci. Technol. 34, $118-126$.

Vilavert, L., Nadal, M., Schuhmacher, M., Domingo, J.L., 2014. Seasonal surveillance of airborne PCDD/Fs, PCBs and PCNs using passive samplers to assess human health risks. Sci. Total. Environ. 466-467, 733-740.

Wang, W., Huang, M.J., Wu, F.Y., Kang, Y., Wang, H.S., Cheung, K.C., Wong, M.H., 2013a. Risk assessment of bioaccessible organochlorine pesticides exposure via indoor and outdoor dust. Atmos. Environ. 77, 525-533.

Wang, W., Huang, M.J., Zheng, J.S., Cheung, K.C., Wong, M.H., 2013b. Exposure assessment and distribution of polychlorinated biphenyls (PCBs) contained in indoor and outdoor dusts and the impacts of particle size and bioaccessibility. Sci. Total. Environ. 463, 1201-1209.

Wang, Y., Cheng, Z., Li, J., Luo, C., Xu, Y., Li, Q., Liu, X., Zhang, G., 2012. Polychlorinated naphthalenes (PCNS) in the surface soils of the Pearl River Delta, South China: distribution, sources, and air-soil exchange. Environ. Pollut. 170, 1-7.

Zereini, F., Alt, F., Messerschmidt, J., Wiseman, C., Feldmann, I., Von Bohlen, A. MÜller, J., Liebl, K., PÜttmann, W., 2005. Concentration and distribution of heavy metals in urban airborne particulate matter in Frankfurt am Main. Ger. Environ. Sci. Technol. 39, 2983-2989.

Zhao, H., Shao, L., Yao, Q., 2005. Microscopic morphology and size distribution of residential indoor $\mathrm{PM}_{10}$ in Beijing City. Indoor. Built. Environ. 14, 513-520. 